\title{
EGFR may couple moderate alcohol consumption to increased breast cancer risk
}

This article was published in the following Dove Press journal:

Breast Cancer:Targets and Therapy

3 October 2009

Number of times this article has been viewed

\author{
Christopher P Mill' \\ Julia A Chester ${ }^{2}$ \\ David J Riese II' \\ 'Purdue University School \\ of Pharmacy, Purdue University \\ Center for Cancer Research, \\ ${ }^{2}$ Purdue University Department \\ of Psychological Sciences, West \\ Lafayette, IN, USA
}

Correspondence: David J Riese II 20 I S. University Street, HANS I I4, Purdue University Center for Cancer Research, West Lafayette,

IN 47907-2064, USA

Tel + I 765494609 |

Fax +I 765496360 I

Email driese@purdue.edu

\begin{abstract}
Alcohol consumption is an established risk factor for breast cancer. Nonetheless, the mechanism by which alcohol contributes to breast tumor initiation or progression has yet to be definitively established. Studies using cultured human tumor cell lines have identified signaling molecules that may contribute to the effects of alcohol, including reactive oxygen species and other ethanol metabolites, matrix metalloproteases, the ErbB2/Her2/Neu receptor tyrosine kinase, cytoplasmic protein kinases, adenylate cyclase, E-cadherins, estrogen receptor, and a variety of transcription factors. Emerging data suggest that the epidermal growth factor receptor (EGFR) tyrosine kinase may contribute to breast cancer genesis and progression. Here we integrate these findings and propose three mechanisms by which alcohol contributes to breast cancer. A common feature of these mechanisms is increased EGFR signaling. Finally, we discuss how these mechanisms suggest strategies for addressing the risks associated with alcohol consumption.
\end{abstract}

Keywords: alcohol, breast cancer risk factor, EGF receptor, matrix metalloprotease

\section{Alcohol and other breast cancer risk factors}

One in eight American women will be stricken with breast cancer, which is the second leading cause of cancer-related mortality among American women. ${ }^{1}$ Approximately $15 \%$ of those breast cancer patients who receive surgery and chemotherapy will experience a recurrence of the disease. This is a major contributor to the fact that one-third of those who develop breast cancer will ultimately succumb to the disease. ${ }^{2}$ Thus, breast cancer remains an important public health and societal issue and more information is needed concerning the causes of breast cancer and risk factors associated with the disease.

In $50 \%$ of breast cancers the only apparent risk factors are gender and age. ${ }^{1,2}$ In the other half of breast cancers the risk factors include genetic factors, environmental factors, age of menarche and menopause, and reproductive history. ${ }^{2}$ The latter factors underscore the contributions of female reproductive hormones to breast cancer risk. ${ }^{2}$

ErbB family receptor tyrosine kinases and their ligands, members of the epidermal growth factor (EGF) family of peptide growth factors, also play significant roles in breast cancer pathogenesis and progression. The ErbB2 receptor tyrosine kinase, also known as HER2/Neu, is overexpressed in a significant fraction of breast tumors and this overexpression correlates with the absence of steroid hormone receptor expression and with poor disease prognosis..$^{3-5}$ Constitutive ErbB2 signaling causes mammary malignancies in transgenic mouse model systems ${ }^{6,7}$ and causes malignant growth transformation in cell culture models of breast cancer. ${ }^{8,9}$ Moreover, agents that target 
ErbB2 are moderately effective at controlling ErbB2-positive breast tumors when these agents are administered as part of a combination chemotherapy regimen. ${ }^{10}$

Although EGF receptor (EGFR) overexpression is observed in breast tumors, ${ }^{11}$ the potential roles that EGFR signaling may have in the development or progression of breast cancer are not as well-characterized as those played by ErbB2. ${ }^{12}$ Nonetheless, EGFR expression and signaling have been postulated to play roles in the genesis, maintenance, or progression of breast tumors. EGFR appears to be of particular relevance to breast cancer stem cells, triple negative tumors, and basal-type tumors. For example, breast cancer stem cells that exhibit elevated EGFR signaling display resistance to endocrine therapy ${ }^{13}$ as well as uncontrolled self-renewal and unlimited proliferation. ${ }^{14}$ Approximately $60 \%$ of basal-type and triple-negative tumors display elevated EGFR expression. Basal-type and triple-negative breast tumors are typically devoid of estrogen receptor (ER) and HER2 (ErbB2/Neu) expression and are therefore resistant to existing targeted therapies. Thus, EGFR is an attractive target in these types of breast tumors. ${ }^{15}$ Indeed, a combination of carboplatin and the EGFR tyrosine kinase inhibitor cetuximab (Erbitux) synergistically inhibits proliferation of basal-type breast cancer cell lines. ${ }^{16}$

Endogenous ligands for ErbB receptors also appear to play important roles in human breast cancers. For example, the EGFR ligand amphiregulin stimulates breast tumor cell motility $^{17}$ and is sufficient and necessary for tumor cell expression of parathyroid hormone-related protein (PTHrP), an important contributor to tumor cell invasion and colonization of bone. ${ }^{18,19}$ Reduced expression of matrix metalloproteases (MMPs) in SCP20 human breast tumor cells is associated with decreased osteoclastic stimulation by these cells and reduced amphiregulin release by these cells. These data suggest that amphiregulin/EGFR signaling is coupled to bone colonization of breast tumor cells and can be regulated by matrix metallproteases. Indeed, the EGFR antagonistic antibody cetuximab or the EGFR tyrosine kinase inhibitor gefinitib inhibits bone metastasis by SCP20 cells in mouse xenograft assays. ${ }^{20}$ Moreover, the fact that EGFR ligands can stimulate ErbB2 signaling through heterodimerization with EGFR $^{21}$ suggests that EGFR and its ligands may play a significant role in at least some ErbB2-dependent breast tumors. Indeed, pharmacological agents that target EGFR or its ligands continue to be investigated as potential breast cancer therapeutics. ${ }^{22-24}$

Several environmental factors appear to contribute to breast cancer risk, including ionizing radiation, pesticides, and diet. ${ }^{2}$ A number of studies have identified an association between moderate alcohol consumption and increased breast cancer risk. ${ }^{25-29}$ For example, average consumption of 14 or more drinks per week in a five-year period prior to breast cancer diagnosis increased breast cancer risk by $82 \%{ }^{30}$

\section{Alcohol may exert its effects via several mechanisms}

There appear to be multiple mechanisms by which alcohol may contribute to breast malignancies or may modulate the behavior of mammary epithelial and tumor cells in vivo and in vitro. Alcohol is metabolized in a variety of tissues, including the breast. Alcohol dehydrogenase converts ethanol to acetaldehyde, which can form adducts of DNA and can cause DNA cross-links and G:A transitions at A:T base pairs. Indeed, acetaldehyde displays weak mutagenic and carcinogenic activity. ${ }^{29,31}$ Xanthine oxidoreductase and aldehyde oxidase are found in breast tissue and metabolize acetaldehyde to reactive oxygen species (ROS), including the superoxide anion free radical $\left(\mathrm{O}_{2}{ }^{\cdot-}\right)$, the neutral hydroxide free radical $\left(\mathrm{OH}^{\circ}\right)$, and hydrogen peroxide $\left(\mathrm{H}_{2} \mathrm{O}_{2}\right)$. These ROS can contribute to breast malignancies via a variety of mechanisms, including DNA mutation, base deletion, and single and double strand breaks. ${ }^{29,31}$

Additional mechanisms may underlie the contributions of ethanol to breast malignancies. Alcohol at a concentration as low as $0.06 \%$ stimulates the expression of estrogen receptor alpha $(\mathrm{ER} \alpha)$ and the estradiol biosynthesis enzyme aromatase in human breast cancer cell lines. ${ }^{32,33}$ In fact, moderate alcohol consumption of $0.7 \mathrm{~g} / \mathrm{kg}$ is associated with an elevated estrogen concentration in the plasma of postmenopausal women. ${ }^{34,35}$ In cell line model systems alcohol concentrations of $0.06 \%$ to $0.6 \%$ stimulate transcription from the estrogen response element ${ }^{36}$ and increased transcription of the progesterone receptor and $\mathrm{pS} 2$, two genes whose transcription is regulated by ER. ${ }^{37}$ Alcohol stimulation of ER-dependent gene expression may account for the observation that alcohol stimulates proliferation in ER-positive MCF7 human breast tumor cells but has no effect on the proliferation of ER-negative MDA-MB-231 and BT-20 human breast tumor cell lines. ${ }^{33}$ However, it is has yet to be demonstrated that changes in ER-dependent gene expression underlie the effects of alcohol on the malignant phenotypes of breast tumor cells.

Alcohol induces other intracellular signaling events. Increased expression of the c-Fos transcription factor is observed in NIH $3 \mathrm{~T} 3$ cells one hour after treatment with $0.2 \%$ alcohol. This increase persists up to 96 hours after treatment with alcohol. ${ }^{38}$ Likewise, alcohol concentrations of $1.3 \%$ to 
$5.1 \%$ stimulate phosphorylation of the c-Jun NH2-terminal protein kinase $(\mathrm{JNK})$, the p38 mitogen-activated protein kinase (p38 MAPK), and phosphatidylinositol 3-kinase (PI3K). ${ }^{39,40}$ Finally, alcohol concentrations as low as $0.12 \%$ inhibit expression of the adhesion molecule E-cadherin and cause an increase in cell migration. ${ }^{41}$ E-cadherin is a tumor suppressor and loss of E-cadherin expression contributes to tumor progression by enhancing metastatic phenotypes. ${ }^{42}$

Metalloproteases are zinc-dependent endopeptidases. These enzymes are expressed in an inactive, secreted, or transmembrane precursor form. The interaction of a zinc ion with three histidine residues and a cysteine residue (cysteine "switch" residue) hold the metalloprotease in an inactive conformation. Metalloproteases can be activated through cleavage by convertases such as furin. ROS can activate metalloproteases by oxidizing the cysteine switch residue, thereby disrupting its interaction with the zinc ion and allowing the enzyme to adopt an active conformation..$^{43}$ Active tumor cell metalloproteases degrade components of the extracellular matrix, such as gelatin and collagens, thereby contributing to tumor cell invasiveness and metastasis. ${ }^{44,45}$ In breast cancer cell lines, alcohol concentrations of $1.3 \%$ to $5.1 \%$ stimulate the expression and secretion of MMPs 2 and 9. ${ }^{39,46,47}$ Thus, it is not surprising that alcohol stimulates invasiveness and anchorage-independent proliferation of MCF7 human mammary tumor cells. ${ }^{32,41}$ Moreover, small interfering RNAs (siRNAs) specific for MMP2 or small molecule inhibitors of MMP2 reduce the effect of alcohol on anchorage-independent proliferation. ${ }^{39}$

Alcohol appears to stimulate metalloprotease activity via a variety of mechanisms. As discussed earlier, alcohol is metabolized to ROS, ${ }^{48-50}$ which then can stimulate metalloprotease activity. ${ }^{51,52}$ Thus, it is reasonable to postulate that ROS and their regulation of metalloproteases mediate at least some of the effects of alcohol on the malignant phenotypes of breast tumor cells. Indeed, ROS scavengers inhibit alcohol stimulation of metalloprotease activity and alcohol stimulation of tumor cell invasiveness. ${ }^{39}$

\section{Alcohol may stimulate tumor cell aggressiveness through increased EGFR signaling}

Experiments in fruit flies indicate that increased signaling of EGFR through Erk, but not through p38 or JNK, inhibits the sedative effects of alcohol. Moreover, the sedative effects of alcohol exposure in fruit flies or alcohol consumption by rats appear more rapidly in animals treated with the EGFR tyrosine kinase inhibitor erlotinib. These data suggest that EGFR signaling modulates pathways that couple alcohol to its behavioral effects. ${ }^{53}$ In subsequent paragraphs we will discuss numerous other observations that support the hypothesis that EGFR signaling couples alcohol to biological responses, particularly malignant phenotypes of breast tumor cells.

Most EGF family peptide growth factors are expressed as transmembrane precursors. Active metalloproteases cleave these precursors, releasing a mature, soluble form of the growth factor that binds ErbB receptors and stimulates their signaling. ${ }^{43}$ Agonists for numerous serpentine $\mathrm{G}$ protein-coupled receptors (GPCRs) regulate the cleavage of EGF family precursors by metalloproteases, thereby enabling GPCR agonists to stimulate ErbB receptor signaling and coupling to biological responses. ${ }^{51,54}$ For example, MMP9 and MMP2 are required for agonists of the $\mathrm{G}_{\mathrm{q}}$-coupled gonadotropin receptor to stimulate EGFR tyrosine phosphorylation and induction of the downstream transcription factors c-Fos and c-Jun. ${ }^{51,55}$ Similarly, the GPCR agonists lysophosphatidic acid (LPA) and carbachol stimulate cleavage and maturation of the precursor form of amphiregulin (AR) by the metalloprotease ADAM17, resulting in enhanced cell migration and increased DNA synthesis. ${ }^{17,56}$ Phenylpherine stimulates cleavage of the precursor form of heparin-binding EGF-like growth factor (HB-EGF) by MMP7, leading to arterial vasoconstriction. ${ }^{51,57}$ GPCR transactivation of EGFR signaling also stimulates the activity of the c-Jun NH2terminal protein kinase ( $\mathrm{JNK}$ ), the p38 mitogen-activated protein kinase (p38 MAPK), and phosphatidylinositol 3-kinase (PI3K). ${ }^{51}$ It should be reiterated that the activity of JNK, MAPK, PI3K, c-fos, and c-jun increases upon treatment with alcohol, ${ }^{39,40,51,55}$ suggesting that alcohol may activate signaling pathways that are also activated by $\mathrm{G}_{\alpha q}$-coupled or $\mathrm{G}_{\alpha \mathrm{i}}$-coupled GPCRs and that may include EGFR and its effectors. Indeed, angiotensin (AT) stimulation of the $\mathrm{G}_{\alpha q}$-coupled AT receptor I leads to ROS production, which in turn stimulates ADAM17-dependent cleavage of HB-EGF. ${ }^{51}$ Recall that alcohol is metabolized to ROS. Consequently, we postulate that alcohol metabolism to ROS and subsequent stimulation of metalloprotease activity by ROS could result in increased processing of EGF family precursor proteins and increased EGFR signaling (Figure 1). Indeed, preliminary data from our laboratory indicates that $1 \%$ alcohol stimulates MCF7 human breast tumor cells to release AR into the culture medium.

Alcohol concentrations of $0.1 \%$ to $0.3 \%$ stimulate the transcription of genes whose promoter contains a cyclic AMP (cAMP) response element (CRE). ${ }^{37}$ Indeed, alcohol stimulates the activity of some adenylate cyclases (ACs), apparently by 


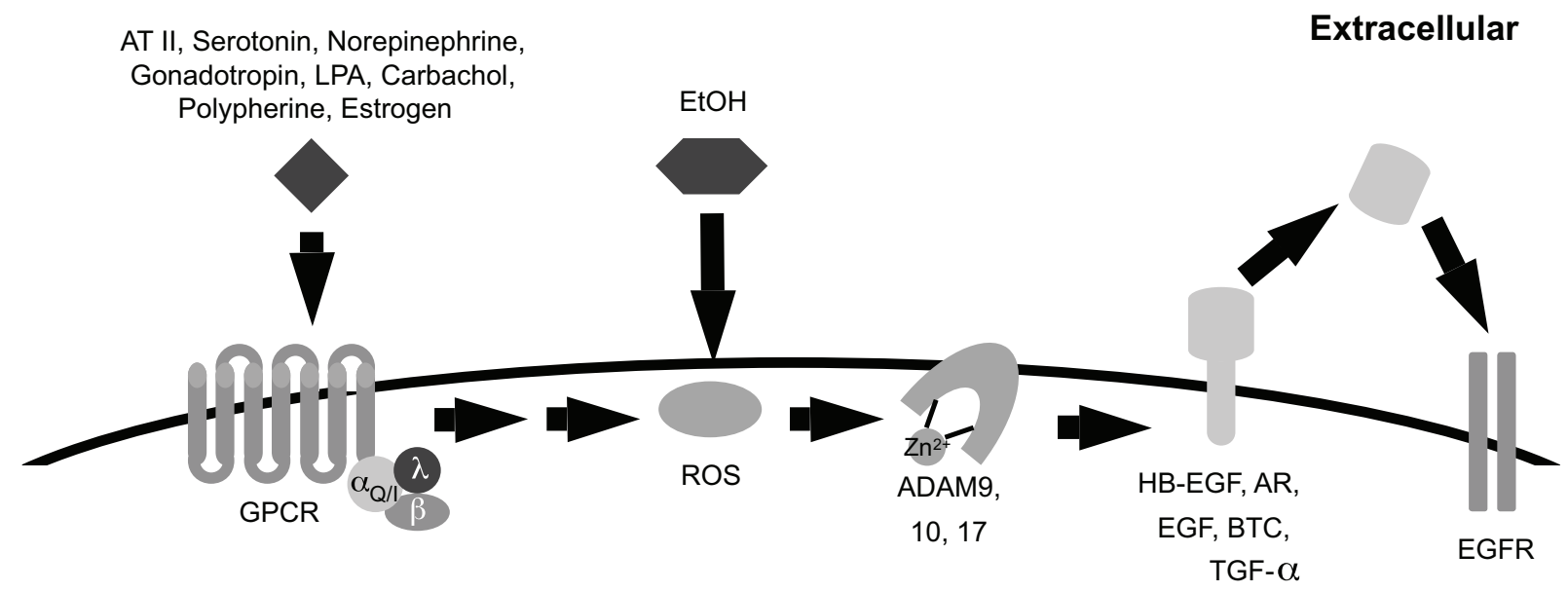

Cytoplasm

\section{Nucleus}

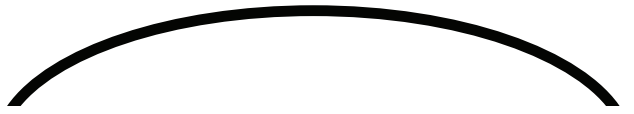

Figure I Alcohol may mimic G-protein coupled receptor transactivation of EGFR. Signaling by $\mathrm{G}_{\mathrm{q} / \mathrm{i}}$-coupled receptors contributes to the production of reactive oxygen species (ROS). These ROS oxidize a cysteine residue in the catalytic cleft of the ADAM, thereby disrupting the interaction between the zinc ion and the ADAM protein. Disruption of this interaction causes the ADAM protein to adopt an active conformation. Active ADAM proteins can then cleave the precursor form of EGF family growth factors. The cleaved factors bind EGFR and stimulate its signaling activity. Because alcohol causes intracellular accumulation of ROS, it is predicted to stimulate EGFR signaling.

Abbreviations: AT II, angiotensin II; LPA, lysophosphatidic acid; EtOH, ethanol; GPCR, G-protein coupled receptor; ROS, reactive oxygen species; HB-EGF, heparin-binding, EGF-like growth factor; AR, amphiregulin; EGF, epidermal growth factor; BTC, betacellulin; TGFalpha, transforming growth factor alpha; EGFR, EGF receptor.

stabilizing the enzyme in the active conformation. ${ }^{58,59}$ This leads to increased cAMP production, protein kinase A (PKA) activity, phosphorylation of the CRE binding protein (CREB) by PKA, and increased transactivation of CRE promoters by phosphorylated CREB. Because the amphiregulin promoter contains a $\mathrm{CRE},{ }^{17}$ it is reasonable to speculate that alcohol may stimulate EGFR signaling through a cAMP-dependent increase in amphiregulin transcription (Figure 2). Indeed, vasoactive intestinal peptide (VIP), which stimulates cAMP production through a $\mathrm{G}_{\alpha \mathrm{s}}$-coupled GPCR, also stimulates EGFR tyrosine phosphorylation in colonic epithelial cells. ${ }^{60}$

As discussed earlier, alcohol stimulates transcriptional activation by the estrogen receptor. The details of the mechanism by which this occurs remain unclear. Nonetheless, alcohol stimulates ER $\alpha$ and aromatase expression ${ }^{32,33}$ and estrogen stimulates ER-dependent TGF $\alpha$ and amphiregulin gene expression. ${ }^{61-63}$ Thus, alcohol may stimulate biological responses in breast tumor cells through ER $\alpha$ stimulation of EGFR ligand expression and EGFR signaling. This hypothesis is consistent with our preliminary observation that $1 \%$ alcohol stimulates MCF7 human breast tumor cells to express AR and release it into the culture medium.

Estrogen can also rapidly modulate cellular signaling pathways in the cytosol and at the membrane in the absence of any direct effect of ER on gene expression. ${ }^{64,65}$
Some of these nongenomic responses are mediated by a GPCR that stimulates $\mathrm{G}_{\alpha \mathrm{i}}$, resulting in activation of matrix metalloproteases and cleavage of the proform of an EGF family growth factor (Figure 1). ${ }^{64}$ Other effects appear to be mediated by $\mathrm{G}_{\alpha s}$, resulting in elevated PKA activity and cAMP accumulation (Figure 2). ${ }^{65}$ As discussed earlier, this could result in elevated amphiregulin expression via the CRE present in the amphiregulin promoter.

EGFR signaling can modulate ER-dependent signaling. ${ }^{64}$ EGFR can couple to the PI3K/Akt pathway, leading to IKK phosphorylation of the estrogen receptor and modulation of ER-dependent gene expression. ${ }^{66}$ EGFR signaling can also couple to increased Erk and Jnk activity, resulting in the phosphorylation of various transcription factors, including CREB-binding protein (CBP). Phosphorylated CBP can dimerize with estrogen receptor, leading to ER-dependent gene transcription. ${ }^{64}$ Thus, EGFR signaling may lie upstream or downstream of ER in alcohol-induced signaling pathways.

As discussed earlier, alcohol inhibits expression of the cell adhesion tumor suppressor protein E-cadherin, leading to an increase in cell migration. ${ }^{41}$ EGFR signaling is coupled to inactivation of the E-cadherin/ $\beta$-catenin complex in tumor cell lines, thereby contributing to metastatic phenotypes. ${ }^{67-70}$ In fact, treatment of lung cancer cell lines with EGFR monoclonal antibodies results in increased 


\section{Extracellular}

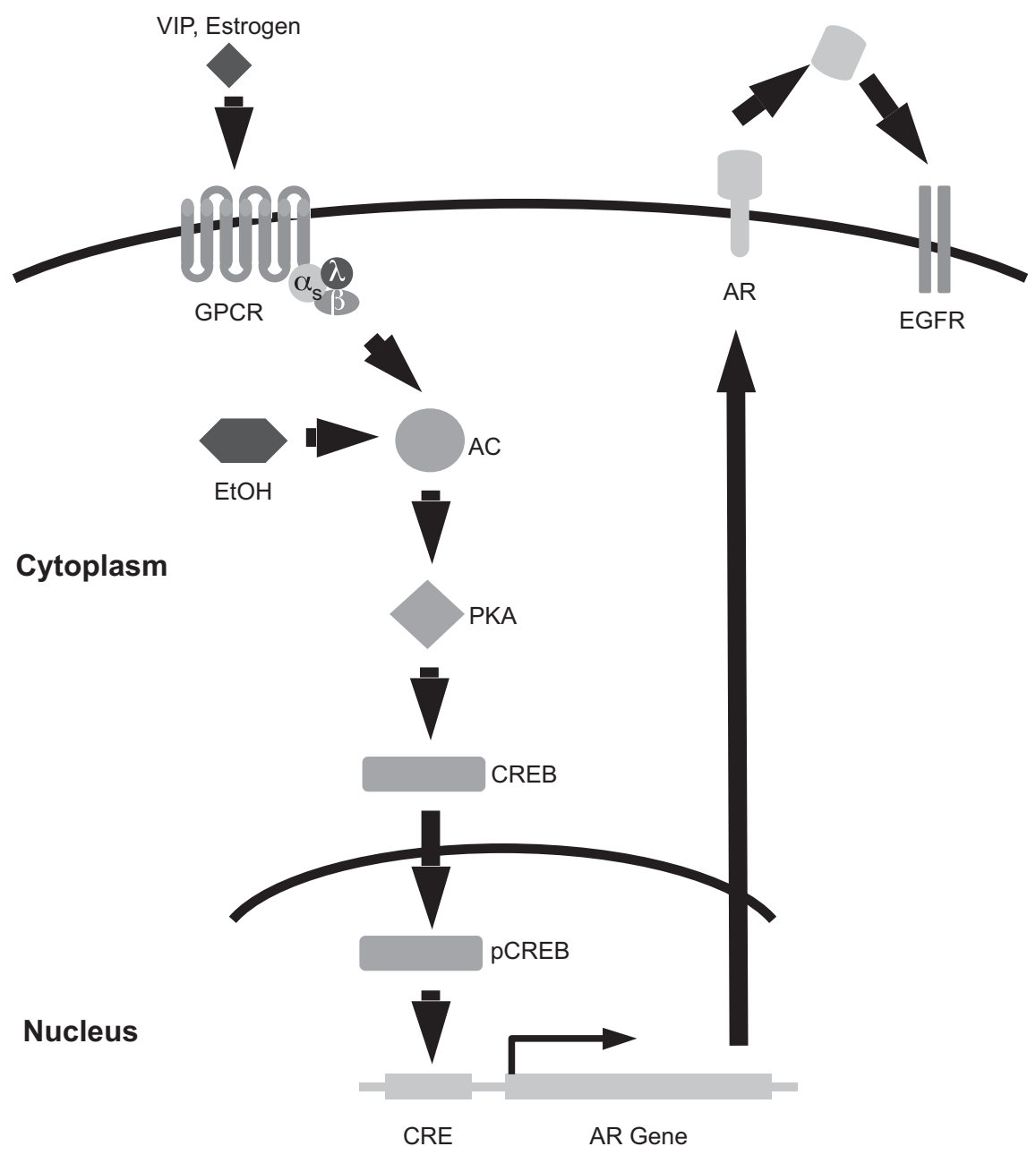

Figure 2 Alcohol may mimic G-protein coupled receptor stimulated transcription of amphiregulin, an EGF family growth factor. Signaling by $\mathrm{G}_{\mathrm{s}}$-coupled receptors stimulates adenylate cyclase $(A C)$ production of cAMP.This increases phosphorylation of the transcription factor CREB (cAMP response element binding protein) by protein kinase $A$ (PKA). CREB promotes the transcription of the EGF family growth factor amphiregulin (AR), resulting in increasing EGFR signaling. Alcohol stabilizes AC in the active conformation, resulting in increased PKA activity. Thus, alcohol is predicted to stimulate AR transcription and EGFR signaling.

Abbreviations: VIP, vasoactive intestinal peptide; GPCR, G-protein coupled receptor; EtOH, ethanol; AC, adenylate cyclase; PKA, protein kinase A; CRE, cyclic AMP response element; CREB, CRE-binding protein; PCREB, phosphorylated CREB; AR, amphiregulin; EGFR, EGF receptor.

E-cadherin expression. ${ }^{71}$ Thus, increased EGFR signaling may be responsible for the decrease in E-cadherin expression observed following alcohol treatment.

A hallmark of EGFR signaling is phosphorylation of EGFR on cytoplasmic tyrosine residues. This phosphorylation creates docking sites for effector binding and coupling. Thus, dephosphorylation of these tyrosine residues by phosphatases negatively regulates EGFR coupling to effector proteins and biological responses. ${ }^{72-74}$ There is emerging evidence suggesting that alcohol enhances EGFR signaling by inactivating phosphatases that catalyze EGFR dephosphorylation (Figure 3). Recall that alcohol is metabolized to ROS in breast tissue. These ROS can oxidize a conserved, essential cysteine residue in the catalytic domain of phosphatases, thereby disrupting the catalytic activity of the phosphatases. ${ }^{49,75,76}$ Therefore, it is plausible to postulate that alcohol may stimulate increased EGFR signaling through ROS-mediated inactivation of the phosphatases that dephosphorylate EGFR tyrosine residues. Indeed, it has been suggested that ultraviolet light and other cellular stresses that contribute to the production of intracellular ROS cause increased EGFR signaling via this mechanism. ${ }^{77}$

Agonist binding to EGFR can cause EGFR heterodimerization with ErbB2, leading to phosphorylation of both receptor molecules and coupling of both receptors to downstream signaling events. Because ErbB2 does not possess soluble agonists, this is an important mechanism by which ErbB2 signaling can be regulated. ${ }^{78}$ This heterodimerization of ErbB2 


\section{Extracellular}
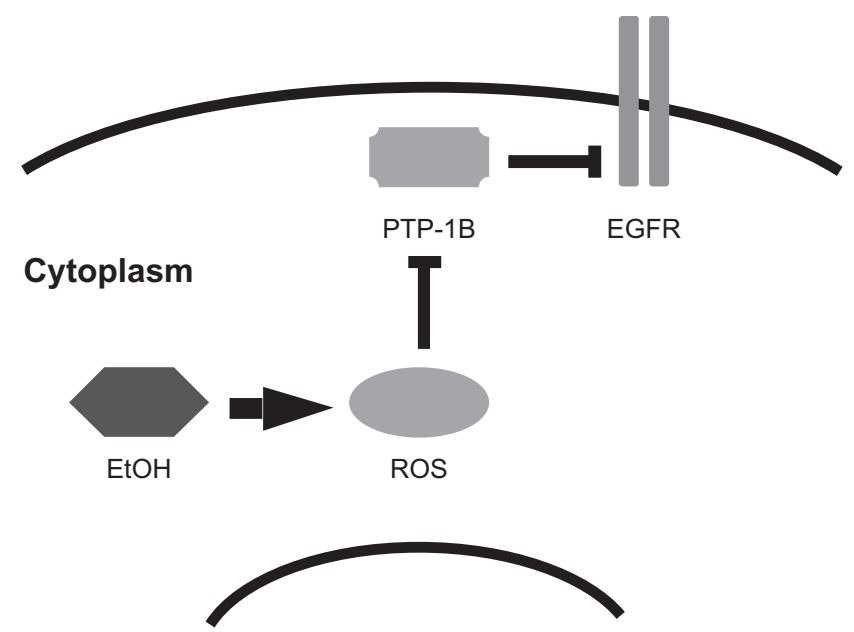

\section{Nucleus}

Figure 3 Alcohol may inhibit phosphatases that negatively regulate EGFR. The protein tyrosine phosphatase PTP-IB inhibits EGFR signaling by catalyzing the dephosphorylation of EGFR tyrosine residues. ROS can oxidize a catalytic cysteine residue of protein phosphatases, thereby inactivating them and leading to increased EGFR signaling. Because alcohol causes intracellular accumulation of ROS, it is predicted to stimulate EGFR signaling.

Abbreviations: $\mathrm{EtOH}$, ethanol; ROS, reactive oxygen species; PTP-IB, protein tyrosine phosphatase IB; EGFR, EGF receptor.

with EGFR may contribute to the effect alcohol has on breast tumor cell behavior. Indeed, this model is supported by the observation that ErbB2 overexpression potentiates the effect of alcohol on invasiveness and other malignant phenotypes of breast cancer cell lines. ${ }^{39}-41,79$ ErbB2 overexpression is also associated with increased transcription of MMP2 and MMP9 $^{39,47}$ and siRNA knockdown of endogenous ErbB2 overexpression is associated with reduced MMP activity. ${ }^{39}$

Finally, amphiregulin induces EGFR coupling to increased expression of MMP2 and MMP9 in breast tumor cell lines; antisense knockdown of amphiregulin expression in the NS2T2A1 breast tumor cell line results in decreased expression of MMP2. ${ }^{17}$ Thus, alcohol stimulation of MMP expression and activity as described in this review may establish a feed forward mechanism that features increased amphiregulin stimulation of EGFR/ErbB2 signaling. This signaling is then coupled to increased expression of MMP2 and MMP9, which contributes to further increases in signaling by the amphiregulin/EGFR/ErbB2 axis and deregulated cellular proliferation, motility, and invasiveness.

Here we postulate three mechanisms by which alcohol may contribute to breast tumor genesis, progression, or aggressiveness. Additional experimentation is necessary to decipher which, if any, of these mechanisms are relevant. These experiments should proceed with an understanding that these mechanisms are not likely to be mutually exclusive. Indeed, at different stages during breast cancer progression distinct mechanisms may be relevant.

The mechanisms discussed here may have important implications in understanding breast cancer progression and potential therapies. Given that alcohol may stimulate estrogen receptor, EGFR, and ErbB2/Her2/Neu signaling, even moderate alcohol consumption may affect the outcome of breast cancer patients whose tumors express these proteins. Moreover, given the central role that ROS and estrogen may have in mediating the effects of alcohol on breast tumor genesis, progression, or aggressiveness, antioxidants and antiestrogens may hold value in blocking the negative effects of alcohol on breast cancer.

\section{Acknowledgments}

We acknowledge support from the National Cancer Institute (R01CA114209 to DJR), the US Army Breast Cancer Research Program (DAMD17-00-1-0416 to DJR), the American Cancer Society (IRG-58-006), the Indiana Elks Foundation, the Purdue University Center for Cancer Research, and the Oncological Sciences Center of Purdue University Discovery Park. The authors report no conflicts of interest in this work.

\section{References}

1. Draper L. Breast cancer: trends, risks, treatments, and effects. Aaohn J. 2006;54(10):445-451; quiz 452-443.

2. DeVita VT, Hellman S, Rosenberg SA. Cancer: principles and practice of oncology. 5th ed. Philadelphia: Lippincott-Raven; 1997.

3. Dean-Colomb W, Esteva FJ. Her2-positive breast cancer: herceptin and beyond. Eur J Cancer. 2008;44(18):2806-2812.

4. Wang SC, Zhang L, Hortobagyi GN, Hung MC. Targeting HER2: recent developments and future directions for breast cancer patients. Semin Oncol. 2001;28(6 Suppl 18):21-29.

5. Horiguchi J, Koibuchi Y, Iijima K, et al. Co-expressed type of ER and HER2 protein as a predictive factor in determining resistance to antiestrogen therapy in patients with ER-positive and HER2-positive breast cancer. Oncol Rep. 2005;14(5):1109-1116.

6. Andrechek ER, Muller WJ. Developmental timing of activated erbB2 expression plays a critical role in the induction of mammary tumors. Cell Cycle. 2004;3(9):1111-1113.

7. Ursini-Siegel J, Schade B, Cardiff RD, Muller WJ. Insights from transgenic mouse models of ERBB2-induced breast cancer. Nat Rev Cancer. 2007;7(5):389-397.

8. Amundadottir LT, Leder P. Signal transduction pathways activated and required for mammary carcinogenesis in response to specific oncogenes. Oncogene. 1998;16(6):737-746.

9. Sheffield LG. C-Src activation by ErbB2 leads to attachmentindependent growth of human breast epithelial cells. Biochem Biophys Res Commun. 1998;250(1):27-31.

10. Park JW, Neve RM, Szollosi J, Benz CC. Unraveling the biologic and clinical complexities of HER2. Clin Breast Cancer. 2008;8(5):392-401.

11. Chrysogelos SA, Dickson RB. EGF receptor expression, regulation, and function in breast cancer. Breast Cancer Res Treat. 1994;29(1):29-40.

12. Rampaul RS, Pinder SE, Nicholson RI, Gullick WJ, Robertson JF, Ellis IO. Clinical value of epidermal growth factor receptor expression in primary breast cancer. Adv Anat Pathol. 2005;12(5):271-273. 
13. O'Brien CS, Howell SJ, Farnie G, Clarke RB. Resistance to endocrine therapy: are breast cancer stem cells the culprits? J Mammary Gland Biol Neoplasia. 2009;14(1):45-54.

14. Ischenko I, Seeliger H, Schaffer M, Jauch KW, Bruns CJ. Cancer stem cells: how can we target them? Curr Med Chem. 2008;15(30):3171-3184

15. Anders C, Carey LA. Understanding and treating triple-negative breast cancer. Oncology (Williston Park). 2008;22(11):1233-1239; discussion 1239-1240, 1243.

16. Hoadley KA, Weigman VJ, Fan C, et al. EGFR associated expression profiles vary with breast tumor subtype. BMC Genomics. 2007;8:258

17. Willmarth NE, Ethier SP. Amphiregulin as a novel target for breast cancer therapy. J Mammary Gland Biol Neoplasia. 2008;13(2): 171-179.

18. Gilmore JL, Scott JA, Bouizar Z, et al. Amphiregulin-EGFR signaling regulates PTHrP gene expression in breast cancer cells. Breast Cancer Res Treat. 2008;110(3):493-505.

19. Lorch G, Gilmore JL, Koltz PF, et al. Inhibition of epidermal growth factor receptor signalling reduces hypercalcaemia induced by human lung squamous-cell carcinoma in athymic mice. $\mathrm{Br} J$ Cancer. 2007;97(2):183-193.

20. Lu X, Wang Q, Hu G, et al. ADAMTS1 and MMP1 proteolytically engage EGF-like ligands in an osteolytic signaling cascade for bone metastasis. Genes Dev. 2009;23(16):1882-1894.

21. Wang Z, Zhang L, Yeung TK, Chen X. Endocytosis deficiency of epidermal growth factor (EGF) receptor-ErbB2 heterodimers in response to EGF stimulation. Mol Biol Cell. 1999;10(5):1621-1636.

22. Diermeier S, Horvath G, Knuechel-Clarke R, Hofstaedter F, Szollosi J, Brockhoff G. Epidermal growth factor receptor coexpression modulates susceptibility to Herceptin in HER2/neu overexpressing breast cancer cells via specific erbB-receptor interaction and activation. Exp Cell Res. 2005;304(2):604-619.

23. Patel D, Bassi R, Hooper A, Prewett M, Hicklin DJ, Kang X. Anti-epidermal growth factor receptor monoclonal antibody cetuximab inhibits EGFR/HER-2 heterodimerization and activation. Int J Oncol. 2009;34(1):25-32.

24. Xia W, Mullin RJ, Keith BR, et al. Anti-tumor activity of GW572016: a dual tyrosine kinase inhibitor blocks EGF activation of EGFR/erbB2 and downstream Erk1/2 and AKT pathways. Oncogene. 2002;21(41): 6255-6263.

25. Key J, Hodgson S, Omar RZ, et al. Meta-analysis of studies of alcohol and breast cancer with consideration of the methodological issues. Cancer Causes Control. 2006;17(6):759-770.

26. Longnecker MP. Alcoholic beverage consumption in relation to risk of breast cancer: meta-analysis and review. Cancer Causes Control. 1994;5(1):73-82.

27. Smith-Warner SA, Spiegelman D, Yaun SS, et al. Alcohol and breast cancer in women: a pooled analysis of cohort studies. JAMA. 1998;279(7):535-540.

28. Zhang SM, Lee IM, Manson JE, Cook NR, Willett WC, Buring JE. Alcohol consumption and breast cancer risk in the Women's Health Study. Am J Epidemiol. 2007;165(6):667-676.

29. Dumitrescu RG, Shields PG. The etiology of alcohol-induced breast cancer. Alcohol. 2005;35(3):213-225.

30. Berstad P, Ma H, Bernstein L, Ursin G. Alcohol intake and breast cancer risk among young women. Breast Cancer Res Treat. 2008;108(1):113-120.

31. Seitz HK, Stickel F. Molecular mechanisms of alcohol-mediated carcinogenesis. Nat Rev Cancer. 2007;7(8):599-612.

32. Etique N, Chardard D, Chesnel A, Merlin JL, Flament S, Grillier-Vuissoz I. Ethanol stimulates proliferation, ERalpha and aromatase expression in MCF-7 human breast cancer cells. Int J Mol Med. 2004;13(1): 149-155.

33. Singletary KW, Frey RS, Yan W. Effect of ethanol on proliferation and estrogen receptor-alpha expression in human breast cancer cells. Cancer Lett. 2001;165(2):131-137.

34. Purohit V. Moderate alcohol consumption and estrogen levels in postmenopausal women: a review. Alcohol Clin Exp Res. 1998;22(5): 994-997.
35. Purohit V. Can alcohol promote aromatization of androgens to estrogens? A review. Alcohol. 2000;22(3):123-127.

36. Fan S, Meng Q, Gao B, et al. Alcohol stimulates estrogen receptor signaling in human breast cancer cell lines. Cancer Res. 2000; 60(20):5635-5639.

37. Etique N, Flament S, Lecomte J, Grillier-Vuissoz I. Ethanol-induced ligand-independent activation of ERalpha mediated by cyclic AMP/PKA signaling pathway: an in vitro study on MCF-7 breast cancer cells. Int J Oncol. 2007;31(6):1509-1518.

38. Volm M, Efferth T, Grabner P, Pommerenke EW. Induction of P-glycoprotein, glutathione S-transferase, catalase, c-FOS and C-ERBB1 in rodent cell lines after exposure to doxorubicin, ethanol and caffeine. Int J Oncol. 1995;6(1):87-92.

39. Ke Z, Lin H, Fan Z, et al. MMP-2 mediates ethanol-induced invasion of mammary epithelial cells over-expressing ErbB2. Int J Cancer. 2006;119(1):8-16.

40. Ma C, Lin H, Leonard SS, Shi X, Ye J, Luo J. Overexpression of ErbB2 enhances ethanol-stimulated intracellular signaling and invasion of human mammary epithelial and breast cancer cells in vitro. Oncogene. 2003;22(34):5281-5290.

41. Meng Q, Gao B, Goldberg ID, Rosen EM, Fan S. Stimulation of cell invasion and migration by alcohol in breast cancer cells. Biochem Biophys Res Commun. 2000;273(2):448-453.

42. Jeanes A, Gottardi CJ, Yap AS. Cadherins and cancer: how does cadherin dysfunction promote tumor progression? Oncogene. 2008;27(55): 6920-6929.

43. Sanderson MP, Dempsey PJ, Dunbar AJ. Control of ErbB signaling through metalloprotease mediated ectodomain shedding of EGF-like factors. Growth Factors. 2006;24(2):121-136.

44. Duffy MJ, Maguire TM, Hill A, McDermott E, O’Higgins N. Metalloproteinases: role in breast carcinogenesis, invasion and metastasis. Breast Cancer Res. 2000;2(4):252-257.

45. Vihinen P, Kahari VM. Matrix metalloproteinases in cancer: prognostic markers and therapeutic targets. Int J Cancer. 2002;99(2): $157-166$.

46. Etique N, Grillier-Vuissoz I, Flament S. Ethanol stimulates the secretion of matrix metalloproteinases 2 and 9 in MCF-7 human breast cancer cells. Oncol Rep. 2006;15(3):603-608.

47. Luo J. Role of matrix metalloproteinase-2 in ethanol-induced invasion by breast cancer cells. J Gastroenterol Hepatol. 2006;21(Suppl 3): S65-S68.

48. Albano E. Alcohol, oxidative stress and free radical damage. Proc Nutr Soc. 2006;65(3):278-290.

49. Das SK, Vasudevan DM. Alcohol-induced oxidative stress. Life Sci. 2007;81(3):177-187.

50. Dey A, Cederbaum AI. Alcohol and oxidative liver injury. Hepatology. 2006;43(2 Supp1 1):S63-S74.

51. Ohtsu H, Dempsey PJ, Eguchi S. ADAMs as mediators of EGF receptor transactivation by G protein-coupled receptors. Am J Physiol Cell Physiol. 2006;291(1):C1-C10.

52. Fischer OM, Hart S, Gschwind A, Prenzel N, Ullrich A. Oxidative and osmotic stress signaling in tumor cells is mediated by ADAM proteases and heparin-binding epidermal growth factor. Mol Cell Biol. 2004;24(12):5172-5183.

53. Corl AB, Berger KH, Ophir-Shohat G, et al. Happyhour, a Ste20 family kinase, implicates EGFR signaling in ethanol-induced behaviors. Cell. 2009;137(5):949-960.

54. Delcourt N, Bockaert J, Marin P. GPCR-jacking: from a new route in RTK signalling to a new concept in GPCR activation. Trends Pharmacol Sci. 2007;28(12):602-607.

55. Roelle S, Grosse R, Aigner A, Krell HW, Czubayko F, Gudermann T. Matrix metalloproteinases 2 and 9 mediate epidermal growth factor receptor transactivation by gonadotropin-releasing hormone. $J$ Biol Chem. 2003;278(47):47307-47318.

56. Gschwind A, Hart S, Fischer OM, Ullrich A. TACE cleavage of proamphiregulin regulates GPCR-induced proliferation and motility of cancer cells. EMBO J. 2003;22(10):2411-2421. 
57. Hao L, Du M, Lopez-Campistrous A, Fernandez-Patron C. Agonist-induced activation of matrix metalloproteinase-7 promotes vasoconstriction through the epidermal growth factor-receptor pathway. Circ Res. 2004;94(1):68-76.

58. Harris RA, Trudell JR, Mihic SJ. Ethanol's molecular targets. Sci Signal. 2008;1(28):re7.

59. Yoshimura M, Pearson S, Kadota Y, Gonzalez CE. Identification of ethanol responsive domains of adenylyl cyclase. Alcohol Clin Exp Res. 2006;30(11):1824-1832.

60. Bertelsen LS, Barrett KE, Keely SJ. Gs protein-coupled receptor agonists induce transactivation of the epidermal growth factor receptor in T84 cells: implications for epithelial secretory responses. $J$ Biol Chem. 2004;279(8):6271-6279.

61. Bates SE, Davidson NE, Valverius EM, et al. Expression of transforming growth factor alpha and its messenger ribonucleic acid in human breast cancer: its regulation by estrogen and its possible functional significance. Mol Endocrinol. 1988;2(6):543-555.

62. Ciarloni L, Mallepell S, Brisken C. Amphiregulin is an essential mediator of estrogen receptor alpha function in mammary gland development. Proc Natl Acad Sci U S A. 2007;104(13):5455-5460.

63. Kenney NJ, Saeki T, Gottardis M, et al. Expression of transforming growth factor alpha antisense mRNA inhibits the estrogen-induced production of TGF alpha and estrogen-induced proliferation of estrogen-responsive human breast cancer cells. J Cell Physiol. 1993;156(3):497-514.

64. Levin ER. Bidirectional signaling between the estrogen receptor and the epidermal growth factor receptor. Mol Endocrinol. 2003;17(3):309-317.

65. Levin ER, Pietras RJ. Estrogen receptors outside the nucleus in breast cancer. Breast Cancer Res Treat. 2008;108(3):351-361.

66. Biswas DK, Iglehart JD. Linkage between EGFR family receptors and nuclear factor kappaB (NF-kappaB) signaling in breast cancer. $J$ Cell Physiol. 2006;209(3):645-652.

67. Al Moustafa AE, Yen L, Benlimame N, Alaoui-Jamali MA. Regulation of E-cadherin/catenin complex patterns by epidermal growth factor receptor modulation in human lung cancer cells. Lung Cancer. 2002;37(1):49-56.

68. Cowden Dahl KD, Symowicz J, Ning Y, et al. Matrix metalloproteinase 9 is a mediator of epidermal growth factor-dependent e-cadherin loss in ovarian carcinoma cells. Cancer Res. 2008;68(12):4606-4613.
69. Jawhari AU, Farthing MJ, Pignatelli M. The E-cadherin/epidermal growth factor receptor interaction: a hypothesis of reciprocal and reversible control of intercellular adhesion and cell proliferation. J Pathol. 1999;187(2):155-157.

70. Lu Z, Ghosh S, Wang Z, Hunter T. Downregulation of caveolin-1 function by EGF leads to the loss of E-cadherin, increased transcriptional activity of beta-catenin, and enhanced tumor cell invasion. Cancer Cell. 2003;4(6):499-515.

71. Al Moustafa AE, Yansouni C, Alaoui-Jamali MA, O’Connor-McCourt M. Up-regulation of E-cadherin by an anti-epidermal growth factor receptor monoclonal antibody in lung cancer cell lines. Clin Cancer Res. 1999;5(3):681-686.

72. Harris DL, Joyce NC. Protein tyrosine phosphatase, PTP1B, expression and activity in rat corneal endothelial cells. Mol Vis. 2007;13: 785-796.

73. Ishino Y, Zhu C, Harris DL, Joyce NC. Protein tyrosine phosphatase-1B (PTP1B) helps regulate EGF-induced stimulation of S-phase entry in human corneal endothelial cells. Mol Vis. 2008;14:61-70.

74. Mattila E, Pellinen T, Nevo J, Vuoriluoto K, Arjonen A, Ivaska J. Negative regulation of EGFR signalling through integrin-alpha1beta1mediated activation of protein tyrosine phosphatase TCPTP. Nat Cell Biol. 2005;7(1):78-85.

75. Barrett WC, DeGnore JP, Keng YF, Zhang ZY, Yim MB, Chock PB. Roles of superoxide radical anion in signal transduction mediated by reversible regulation of protein-tyrosine phosphatase 1B. J Biol Chem. 1999;274(49):34543-34546.

76. Robinson KA, Stewart CA, Pye QN, et al. Redox-sensitive protein phosphatase activity regulates the phosphorylation state of $\mathrm{p} 38$ protein kinase in primary astrocyte culture. J Neurosci Res. 1999;55(6): 724-732.

77. Carpenter G. Employment of the epidermal growth factor receptor in growth factor-independent signaling pathways. J Cell Biol. 1999;146(4):697-702.

78. Riese DJ 2nd, Stern DF. Specificity within the EGF family/ErbB receptor family signaling network. Bioessays. 1998;20(1):41-48.

79. Aye MM, Ma C, Lin H, Bower KA, Wiggins RC, Luo J. Ethanol-induced in vitro invasion of breast cancer cells: the contribution of MMP-2 by fibroblasts. Int J Cancer. 2004;112(5):738-746.
Breast Cancer: Targets and Therapy

\section{Publish your work in this journal}

Breast Cancer: Targets and Therapy is an international, peerreviewed open access journal focusing on breast cancer research, identification of therapeutic targets and the optimal use of preventative and integrated treatment interventions to achieve improved outcomes, enhanced survival and quality of life for the cancer

\section{Dovepress}

patient. View the full aims and scopes of this journal here. The manuscript management system is completely online and includes a very quick and fair peer-review system, which is all easy to use. Visit http://www.dovepress.com/testimonials.php to read real quotes from published authors. 